\title{
A arte postal/ arte-correo/ mail art como sistema
}

José Luis Jobim

Resumo: $\mathrm{O}$ artigo aborda a natureza da arte postal/ arte-correo/mail art, focalizando predominantemente uma de suas manifestaçōes: as chamadas revistas-coletâneas (assembling magazines). Busca refletir sobre a maneira como as comunidades artisticas reunidas em torno dessas publicaçōes tinham certos conceitos compartilhados (dos quais nem sempre estavam autoconscientes). Muitas vezes nào percebiam que suas próprías declarações sobre as práticas de edição que operavam contradiziam os principios apregoados para elas. Palavras-chave: arte postal/arte-correo/ mail art.

Abstract: This paper has been devoted to the approach of mail art and is strongly emphasizing one of its artistical manifes. tations: the so called assembling magazines. It looks forward to musing the way how artistical communities were always surrounding mail art publication and sharing certain concepts even when most of their ideas were conceived in a non-self-consctous way. Many times the communities curiously could not perceive that their own conceptions related to the operated edition practise produced contradictory effects against the principles defended by their own members. Keywordst postal art, post-office art, mail art. 
Neste breve trabalho, trataremos da arte postal/ arte-correo/ mail art. Começamos por esclarecer que não se trata de um movimento "brasileiro" (nem "uruguaio", "argentino", "norte-americano", "italiano", "húngaro" ou qualquer coisa parecida), pois a sua simultaneidade e a circulação de seus produtos em vários espaços nacionais desautorizam a possível pretensão de qualificá-la com apenas um adjetivo nacional. Trata-se, portanto, de um fenômeno transnacional que tem brasileiros como participantes, o que pode gerar uma perspectiva diferente para sua análise.

Mesmo quando se trata apenas de literatura nacional, é sempre interessante observar como um ponto de vista "externo" pode verbalizar modos de ver e descrever o que se faz no Brasil. Quando a produção poética brasileira contemporânea é julgada a partir de um ângulo externo, de uma visão latino-americana por exemplo, isto pode introduzir diferentes formas de tratamento de autores e obras. Os modos de enquadramento, as denominações dos grupos e as maneiras de contar a história desses grupos, assim como quem é visto como pertencendo a eles não necessariamente coincidem com o que predomina no Brasil. Veja-se, por exemplo, o que o professor venezuelano Juan Pintó diz sobre o concretismo e a vanguarda, ${ }^{1}$ ou a nota preliminar do escritor argentino Ariel Canzani para uma seleção de poemas da "poesia (instauração) Praxis": "este grupo [Praxis] está em guerra permanente com o grupo 'concreto' e [...] por uma simples vírgula são capazes de escrever uma introdução de quatro volumes"2

Se tratarmos de movimentos que descendem das chamadas "vanguardas" do início do século xx, como a Arte Postal/ arte-correo/ mail art, podemos chamar a atenção sobre alguns aspectos. Entre eles, destacamos: 1) a fluidez na autodefinição dos produtores, alguns definindo-se como "poetas", outros como "artistas plásticos" fluidez provavelmente derivada do caráter muitas vezes ao mesmo tempo verbal

1 "Este movimento brasileiro [o concretismo], fortemente entroncado com a vanguarda de seu país, representada por homens como João Cabral de Melo Neto, Ronald de Carvalho, Mário de Andrade, Manuel Bandeira e Murilo Mendes, deixará forte influência em países como Espanha, Bélgica, Chile e França." (Todas as traduçōes apresentadas neste trabalho são minhas.) PINTO, Juan. La poesia experimental. Merida (Venezuela): Universidad de los Andes, 1983, p. 14. Segundo a quarta capa do livro, Pintó era professor e diretor da Faculdade de Letras da Universidad de Los Andes.

2 CANZANI, Ariel. Breves consideraciones sobre la poesía (instauración) Praxis. Cormoran y delfin; revista planetaria de poesia, Ano 6, Viaje 19, out. 1969, p. 29-31. Depois de introduzir o tópico "Poema-Processo", Canzani diz que existem vozes isoladas que cultivam estas novas formas de poesia: "os pequenos pliegos que agrupan a poetas de diversas ciudades, como 'S.L.D.', Suplemento/ Literatura/ Difusión), dirigido por Joaquim Branco, desde Cataguazes, en el estado de Minas Gerais." CANZANI (1969), p. 31. 
e visual daquela produção artística; 2) o aparecimento de novos circuitos artísticos que não se limitam às fronteiras nacionais, ${ }^{3}$ nem aos lugares mais tradicionais (editoras, museus, galerias, universidades etc.); 3) a colocação em xeque das formas de organização, controle e seletividade vigentes nos circuitos mais institucionalizados. Em nosso percurso, começaremos por discutir sumariamente certa linha de tratamento da história literária que vê não só a literatura brasileira, mas também as das antigas colônias ibéricas, como evoluindo de um período de "imitação" para um de "criação autônoma", não por acaso coincidindo com a independência, o que passa a ser questionado por uma produção que se pretende transnacional.

A seguir, depois de sumariamente explicar a natureza da arte postal/arte-correo/ mail art, focalizaremos predominantemente uma de suas manifestações: as chamadas revistas-coletâneas (assembling magazines), buscando refletir sobre a maneira como as comunidades artísticas reunidas em torno destas publicações tinham certos conceitos compartilhados (dos quais nem sempre estavam autoconscientes), organizavam-se a partir destes conceitos e, muitas vezes, não percebiam que suas próprias declarações sobre as práticas de edição que operavam contradiziam os princípios apregoados para elas. Para isto, será fundamental o uso dos depoimentos de grande número dos editores destas publicações, no catálogo da exposição realizada em Iowa City, entre 7 e 21 de setembro de 1996, em que o curador, Stephen Perkins, coletou depoimentos de um grande número de editores e ex-editores.

Vamos, então, à primeira parte da argumentação.

\section{História literária: entre "imitação" e "criação"}

Circula já há muito tempo nas Américas certo tipo de discurso que culpa as antigas colônias ibéricas por seu "atraso" A referência é frequentemente econômica, mas contamina também o modo de ver a literatura e a cultura.

Junto com a ideia do "atraso" vem também a perspectiva de que é necessário superá-lo e uma série de propostas para a "modernização" no mais das vezes

3 Como é uma arte de circulaçāo transnacional, e os autores querem ser entendidos por quem não fala sua língua, há muitas vezes uma combinação de imagens (que não necessitam de "explicação verbal") com palavras, frequentemente em língua que não é a do autor, mas a que ele julga de maior possibilidade de compreensão no circuito internacional.

146. JOBIM, José Luís. A arte postal/ arte-correo/ mail art como sistema 
construídas a partir da história das ex-metrópoles. Cria-se uma imagem de que há uma receita para passar do "atraso" à "modernização" e de que existem etapas para sua superação.

No campo econômico, ainda é corrente o argumento de que há determinado caminho para a "modernização", que passa necessariamente por certas etapas, e de que a ultrapassagem sucessiva destas etapas (modelizadas à feição das percorridas pelas antigas ou pelas novas metrópoles) poderia conduzir ao modelo desejável de "atualização", de aggiornamento. Esse argumento não leva em conta o fato de que é impossível às ex-colônias refazer "etapas" das ex-metrópoles, visto que teriam de reduplicar o próprio sistema colonial dentro do qual foram espoliadas no passado. É importante assinalar, assim, que a ideia de "atraso" da América Latina em relação às suas antigas metrópoles pressupõe: 1) um apagamento da relação colonial, com suas consequências econômicas e culturais; 2) uma tentativa de continuidade de um quadro de referência que coloca as (ex)metrópoles em uma posição hierarquicamente superior às (ex)colônias.

Nessa direção, ecoa certa linhagem de pensamento presente inclusive entre nossos historiadores da literatura no século xx, linhagem esta que trabalha com o seguinte raciocínio básico: no período colonial, a literatura brasileira teria primeiramente "imitado" a literatura portuguesa; depois, com a independência e com o romantismo, teria passado a desenvolver uma dicção própria, "autônoma”, "individual" etc. É claro que há variações até engenhosas, como a de Roger Bastide, que argumenta que a imitação era um modo político de mostrar que na colônia também havia escritores capazes de produzir à moda metropolitana, com competência:

Para compreender bem a literatura brasileira dos séculos XvII e XviII e a influência que a literatura portuguesa exerceu sobre ela, devemos partir da "situação colonial". Não basta mostrar que as "modas" lusas, como a da Arcádia, passavam da metrópole para a colônia, apesar da diversidade das sociedades, a primeira baseada na família particularista, a segunda, na família patriarcal. É preciso entender que o "meio interno" explica esse fenômeno de difusão e que essa difusão é, acima de tudo, um protesto político. Na verdade, ela se reveste mais de suas formas de "cópia servil" quando o nativismo está se desenvolvendo, quando a opressão econômica se torna mais difícil de suportar, quando em cada cidade, na praça central, erguem-se o palácio do governador e a prisão. Trata-se, portanto, de mostrar que os crioulos podem realizar obras estéticas tão bem ou até melhor do que os metropolitanos, que os "nativos" não são "bárbaros", que devem ser comandados de fora, mas que atingiram a maturidade estética, que podem se governar sozinhos. Não 
é impunemente que a conspiração de Tiradentes contra Portugal recrutou-se entre os escritores que mais imitavam as modas literárias "lusas". Vamos encontrar nas literaturas "coloniais" atuais, de língua inglesa ou francesa, o mesmo fenômeno repetindo-se tanto atualmente quanto no passado. ${ }^{4}$

Nesse tipo de versão há alguns problemas, começando pela ideia de afiliação única do arcadismo a Portugal, pois sabe-se hoje que, sem prejuízo das relações luso-brasileiras, deve-se considerar o arcadismo como "parte de um amplo fenômeno de civilização que abrange a Itália, a Espanha, a França, Portugal, o Brasil e outros países." Não nos interessa aqui recordar os argumentos específicos sobre essa questão, mas, isto sim, lembrar o quadro de referências maior em que ela se insere (quadro de referências que inclui a tese de que, no Brasil, passamos da fase da "imitação", no período colonial, para a de "criação", no período pós-independência, a partir do romantismo). Por isto, voltemos ao fio principal da argumentação, lembrando que ela também é retomada pelos próprios escritores brasileiros no modernismo. Em 1924, Mário de Andrade escreve em carta a Carlos Drummond de Andrade:

Nós, imitando ou repetindo a civilização francesa ou alemã, somos uns primitivos, porque estamos ainda na fase do mimetismo. Nossos ideais não podem ser os da França porque as nossas necessidades são inteiramente outras, nosso povo outro, nossa terra outra etc. Nós só seremos civilizados em relação às civilizações o dia em que criarmos o ideal, a orientação brasileira. Então passaremos da fase do mimetismo pra fase da criação. Então seremos universais, porque nacionais. ${ }^{6}$

Então, passar da "fase do mimetismo" para a "fase da criação" torna-se relevante, sem que se perceba o quanto se reproduz uma série de categorias de pensamento de momentos anteriores da literatura e da cultura brasileira. Quando o romantismo passou a combater a poética da imitação e da emulação (que não esteve vigente

\footnotetext{
4 BASTIDE, Roger. Sociologia e literatura comparada. Literatura e Sociedade, São Paulo, Departamento de Teoria Literária e Literatura Comparada da USP, n. 9, p. 264-269, 2006. Originalmente publicado em Cahiers Internationaux de Sociologie, n. 17, jul./dez. 1957.

5 CANDIDO, Antonio. Prefácio. In: SERNA, Jorge Antonio Ruedas de la. Arcádia: tradição e mudança. São Paulo: Edusp, 1995, p. XI-XVI, p. XIII.

6 ANDRADE, Mário. Carta 4 (sem data, 1924). In: Correspondência de Carlos Drummmond de Andrade e Mário de Andrade. Rio de Janeiro: Bem-te-vi, 2002, p. 70.
}

148 - JOBIM, José Luís. A arte postal/ arte-correo/ mail art como sistema 
apenas na Península Ibérica), poética esta predominante nos séculos XVII e XVIII, e qualificou negativamente a atitude de eleger certo universo de autores e obras como modelos a serem seguidos (ao mesmo tempo em que apontava para a necessidade de criar obras que espelhassem não um paradigma textual anterior, mas a suposta personalidade única e original do escritor e do país em que este se inseria), isto significou também o estabelecimento de um parâmetro regulador da produção literária: os poemas do arcadismo, por exemplo, passaram a ser vistos como "pouco criativos", ressaltando-se o "mimetismo" implícito na adequação dos textos aos modelos neoclássicos de escritura, de onde derivariam as regras de elaboração poética dos árcades e à luz dos quais seriam aprovados ou recusados no século XVIII. ${ }^{8}$

O "atraso" e o "mimetismo" funcionam, em conjunto, para criar uma ideia de que as ex-colônias sempre produzem a posteriori, conforme modelos importados da metrópole. De fato, esse pensamento ignora certa sincronia na produção literária, não somente entre ex-colônias e ex-metrópoles, mas entre todas estas e outras nações, em momentos históricos diversos.

De todo modo, avançando no tempo, se examinarmos o pensamento das vanguardas literárias do início do século $\mathrm{xx}$, podemos constatar que estas muitas vezes reciclaram e radicalizaram elementos já presentes no romantismo.

Ao tratarmos de períodos ou movimentos literários, é interessante observar como o contexto em que se inscreve o escritor que fala sobre sua poética acaba de alguma forma projetando-se sobre seu próprio discurso. Ao evocarem ou justificarem as razões de produzir sua arte de tal ou qual modo, com frequência os escritores se

7 Cf. HANSEN, João Adolfo. A sátira e o engenho: Gregório de Matos e a Bahia do século XVII. Săo Paulo: Companhia das Letras, 1989.

8 Antonio Candido ressalta a ambiguidade da atitude dos românticos em relação aos árcades, ao mesmo tempo condenando-os pela subserviência a padrões literários vistos como imitação dos metropolitanos e adotando-os como referência local, como prova de que já havia atividade literária no Brasil antes da Independência. Cf. CANDIDO, Antonio, op. cit., p. XII: "Quando focalizamos o nosso Arcadismo, devemos lembrar que para os românticos ele foi em grande parte um fenômeno de subserviência em relação à literatura metropolitana, e a Metrópole era algo que logo depois da independência parecia necessário rejeitar em todos os campos. Mas, ao mesmo tempo, foi tido como prova de continuidade da vida do espírito no Brasil, além de justificativa e fonte das manifestaçōes literárias dos próprios românticos, despertando neles, contraditoriamente, muito orgulho de tipo genealógico. Portanto, funcionou na posteridade imediata, senão como modelo estético (salvo no que toca ao indianismo dos dois épicos), certamente como fator positivo no sentimento de autonomia, que enformava então o projeto cultural das geraçōes contemporâneas da Independência ou imediatamente posteriores."

Teresa revista de Literatura Brasileira [10|11]; São Paulo, p. 142-161, 2010. - 149 
dirigem a referentes em relação aos quais o sentido do que estão produzindo se delineia. Assim, se, por um lado, na poética da imitação e da emulação ficava claro que havia um cânon de autores e obras que, por serem exemplares, serviam de referência modelar, por outro lado, principalmente após o romantismo emerge uma noção de produção artística bem diferente. Enquanto a poética anterior valorizava o passado, em que buscava o exemplo, o modelo, os românticos valorizavam a estética da expressão do eu autoral, a sua presença na origem da obra, o presente do artista em oposição ao passado de sua arte.

A luta contra as normas neoclássicas no período romântico é feita, entre outras coisas, alegando-se que o próprio pressuposto de produzir um novo classicismo com suas noções de exemplaridade e uso dos clássicos como modelo - não teria cabimento, pois um novo tempo exigiria uma nova poética. Uma poética do hoje seria "melhor" do que a do ontem, por definição. Este é um traço comum também às vanguardas do século $\mathrm{xx}$ que declaram obsoleta toda a produção literária anterior e propõem uma "nova" literatura - a delas - como a única a ter valor.

De certo modo, o que as vanguardas artísticas no início do século $\mathrm{xx}$ faziam era produzir certa "descrição" de aspectos do passado, ainda que para denegá-los, selecionando nesta "descrição" os aspectos em relação aos quais desejavam marcar sua diferença. Ao se criar essa imagem do passado para contrapor-se a ela, constrói-se também uma relação que poderia ser discutida, começando-se com o que se escolheu para configurar como "passado", com uma análise discursiva dos interesses que presidiram as escolhas feitas, e terminando-se com a constatação de que, ao definir a produção artística do presente por contraste ou por rejeição da produção artística do passado, de certa maneira, as vanguardas também ecoam a voz de que discordam. ${ }^{9}$

Se quiséssemos pensar em outra chave a relação das vanguardas do início do século $\mathrm{xx}$ com a literatura anterior, talvez pudéssemos, em vez de tentar ignorar as ligações, levar em conta que elas têm com esta uma relação diferente. Com efeito, muitos grupos do novecentos ainda têm como referência autores e obras literárias do passado, mas não como exemplo, modelo a ser seguido. Como a autoimagem do vanguardista é fortemente marcada pela ideia de sua pretensa autonomia e singularidade genial, ele não se sente constrangido a acolher respeitosamente os paradigmas herdados.

9 Desenvolvi mais detalhadamente este argumento em JOBIM, J. L. "Para uma discussão sobre a percepção e valorização do 'novo' na literatura do século XX". In: HENRIQUES, Ana Lúcia de Souza. Literatura e comparativismo. Rio de Janeiro: Universidade do Estado do Rio de Janeiro, 2005, p. 71-84.

150. JOBIM, José Luís. A arte postal/ arte-correo/ mail art como sistema 
Se quiséssemos arriscar uma generalização, poderíamos argumentar que é numeroso o grupo de artistas do século xx que se apropria da "tradição" de modo lúdico e arbitrário, conforme os interesses mais momentâneos das estruturas artísticas que se constroem. Assim, parece que, em substituição ao que se propunha nas práticas da arte ocidental até, pelo menos, a primeira metade do século XVIII - ou seja, em substituição à regularidade e ao caráter iterativo da emulação, das práticas de imitação que se sucediam, mas traziam certo conforto de retorno à esfera do já conhecido -, emerge uma nova pauta em que mesmo a integração do já conhecido aspira a ter a marca do imprevisto, do aleatório, do contingente.

Será que podemos dizer que esta arte do presente, sem a garantia de uma relação regular e estável com a do passado, perde totalmente qualquer pretensão à regularidade, à iterabilidade, à recursividade? Talvez fosse mais adequado argumentar que a incorporação dos novos elementos na própria operação artística pode constituir também uma regularidade, uma reiteração, uma recursividade, uma "tradição", mesmo que de curta duração.

A partir do século $\mathrm{xx}$, é importante notar também a complexidade cada vez maior das sociedades em que a produção artística se insere ${ }^{10}$ e a crescente facilidade de comunicação, o que permite um incremento significativo nas trocas e transferências culturais e literárias. O circuito das obras e artistas passa a abranger lugares muito distantes das grandes cidades onde tradicionalmente se desenvolveu. Também se desenvolvem técnicas e ideias não só para a criação de novas formas, mas também de novos suportes para a arte, de novos lugares para expô-la e modos de divulgá-la. A seguir, falaremos de uma experiência singular nesse sentido: a arte postal que, nas palavras do poeta uruguaio Clemente Padin, teve seu desenvolvimento extremamente favorecido pela introdução do fax e do correio eletrônico."

10 Mesmo dentro de um mesmo movimento artístico, a complexidade se manifesta. É o que Mário de Andrade observa, em carta a Manuel Bandeira (10/11/1926): "E o chamado Modernismo? Mas eu queria saber quem no mundo poderá definir o Espírito Moderno sem incluir dentro dele as orientaçōes mais dispares!" (MORAES, Marcos Antonio. Correspondência de Mário de Andrade \& Manuel Bandeira. São Paulo: Edusp, IEB, 200o, p. 322). 11 Cf. PADIN, Clemente. Assembling Magazines: Ovum s Saga. In: PERKINS, Stephen (curator \& editor). Assembling Magazines: International Networking Collaboration. Exhibition Catalogue. An Exhibition at Subspace. lowa City, September, 1996, p. 29-30, p. 29: "O fax e o correio eletrônico, ao impulsionarem, interconectarem e acelerarem a comunicação, permitiram a reproduçāo e desenvolvimento deste movimento criativo até o ponto em que é considerado, hoje, um dos paradigmas de networking." 


\section{A arte postal}

Segundo Joaquim Branco, ${ }^{12}$ a mais antiga exposição da Arte-Correio foi o New York Card Show, organizado por Ray Johnson em 1970 nos Estados Unidos; na América do Sul, a primeira mostra realizou-se em 1974, na Galeria U de Montevidéu, coordenada por Clemente Padin, com o título de Festival de la Postal Creativa, de 11 a 24 de outubro. Dessa mostra participou Joaquim Branco, com outros poetas brasileiros, num total de quatrocentos e oitenta artistas.

O poeta de Cataguazes diz que foi por intermédio de uma "corrente postal" - enviada em 1974 por Robert Rehfeldt (Alemanha), Bálint Szombathy (Iugoslávia), Jorge Caraballo (Uruguai) e Horacio Zabala (Argentina) - que a Arte-Correio chegou ao Brasil, exatamente para o poeta pernambucano Paulo Bruscky, que se tornou não só o pioneiro do movimento no Brasil, mas também o seu maior divulgador. Eis a concepção de Joaquim Branco sobre a arte postal:

Consiste a arte postal na veiculação do poema pelo correio, utilizado não apenas como meio de comunicação, mas como suporte formal e conteúdo ao qual o cartão - principal componente -, o envelope, o selo e outros elementos também podem se integrar. O poema postal circula basicamence de poeta para poeta, e esta foi a resposta dos poetas, num dado momento cultural, às dificuldades criadas pelas editoras, pela censura (imposta pelas ditaduras dos países sul-americanos) e pelos veículos tradicionais, que não divulgam o produto de vanguarda.

Impedido de atuar por todos esses fatores, o poeta lançou mão do cartão "fabricado" por ele mesmo, adicionando a ele carimbos, slogans, selos próprios e reproduzindo em xerox a maior parte dos trabalhos. Era o artesanal unido ao prático favorecendo a veiculação das mais variadas formas de vanguarda como a Pop-Art, Minimal-Art, Arte Povera, Poesia Visiva, Junk-Art, Arte Conceitual, Concretismo, Poema-Processo e outras existentes. ${ }^{13}$

12 Todas as informações constam da tese de doutorado de RIBEIRO FILHO, Joaquim Branco. Uma provincia com o selo da poesia. Rio de Janeiro: UERJ, 2006. No que diz respeito a este poeta, complementamos dados com informações fornecidas pelo próprio, a quem devemos nossos agradecimentos, pois, sem o acesso que nos deu a seu rico acervo pessoal, não teria sido possivel elaborar este trabalho.

13 Cf. RIBEIRO FILHO, Joaquim Branco, op. cit. Ele acrescenta: "Na remessa dos postais ou nos envelopes, 'os selos, as etiquetas das agências, os carimbos e o desgaste do transporte estruturam as circunstâncias fortuitas da própria obra. Também são pontos fundamentais neste tipo de poema: a) A introdução dos mais diferentes materiais, além da cartolina, como o acrílico, a madeira, espelhos etc.;

152. JOBIM, José Luís. A arte postal/ arte-correo/ mail art como sistema 
Para Joaquim Branco, no Brasil a arte postal foi o veículo mais adequado encontrado pelos poetas na luta para atingir o mercado externo, e a valorização e a multiplicação do movimento, da década de 1970 para cá, coincidiram com o redimensionamento e a adequação das vanguardas a um meio mais rápido de realização e divulgação: "Por esse sistema alternativo, artistas do mundo inteiro vieram a se comunicar, e desse primeiro estágio os trabalhos passaram ao público principalmente com o sucesso das exposições."14 Dentro do movimento de arte postal, é interessante assinalar o papel assumido por essas exposições dos trabalhos produzidos. Parece que elas têm como "modelo negativo" certo conceito de "seleção" subjacente aos lugares tradicionais de mostras artísticas (museus, galerias, espaços culturais etc.), de modo que os artistas postais constroem uma imagem de inclusão não seletiva por oposição a uma suposta exclusão seletiva (deles) que atribuem àqueles lugares.

Joaquim Branco argumenta que, ao contrário de todas as outras vanguardas dos anos 1960-70 que precederam a arte postal, esta, ainda que se delineasse como um movimento, não teria propriamente um aparato teórico com planos, propostas, manifestos ou assinaturas por meio dos quais se estabeleceriam os meios e projetos de sua atuação. ${ }^{15}$ De fato, corroborando o seu argumento, Ely Raman, em seu

b) A transparência, por permitir ao manipulador da obra ver o seu conteúdo, devassando-Ihe a estrutura, que pode ser constituída de barbantes, moedas, pílulas, clipes, letras de plástico ou de metal, fibras, sementes, esparadrapo etc;

c) A troca de endereços e a publicação de catálogos e antologias contendo geralmente o endereço de cada participante, mesmo que ele resida na regiāo mais remota;

d) As exposições, que às vezes são imensas mostras de cartōes-poemas, onde o público pode manipular, participar e vir a ser coautor de diversos trabalhos expostos, além de poder conhecer de perto e em pouco tempo tudo o que está se fazendo em várias partes do mundo;

e) Os muitos museus experimentais da Europa e os centros de cultura alternativa da América;

f) Mais do que os museus, os arquivos e as caixas postais, em torno dos quais se concentravam grupos de poetas, editavam-se boletins, 'correntes', por meio dos quais se aglutinavam os movimentos. Entre esses arquivos, podemos citar o Parachutes Center for Cultural Affairs, no Canadá; o Small Press Archive, na Bélgica; o Bruscky Arquivo, no Brasil. Entre os boletins e pequenas publicaçōes, estāo o Info, editado por Klaos Groh، do International Artist Cooperation, na Alemanha; o Cambiu, informativo do Centro de Arte Brasileira de Informação e Uniāo, editado por Paulo Bruscky, Daniel Santiago, Sílvio Hansen, J. Medeiros, Unhandeijara Lisboa, Marconi Notaro e outros; o Tabu, editado por Joaquim Branco e P. J. Ribeiro, de Cataguases (MG)."

14 RIBEIRO FILHO, Joaquim Branco, op. cit.

15 Idem, ibidem: "Nesse ponto tratava-se de uma corrente cuja ação era mais natural e menos preocupada com parâmetros de comportamento, táticas ou qualquer tipo de controle sobre seus participantes. Mesmo porque, desde o seu início, nunca se concretizou qualquer tipo de liderança grupal ou individual."

Teresa revista de Literatura Brasileira [10|11]; São Paulo, p. 142-161, 2010 . 153 
depoimento sobre os anos em que coeditou 8X1O PORTFOLIO (1970-1972), diz que estava "muito ocupado produzindo arte, em vez de falando sobre ela".16

No lugar daquelas (tradicionais...) propostas vanguardistas, que visavam a antecipar-se às manifestações artísticas, explicando-as e direcionando-as, haveria apenas uma teorização escrita depois que o próprio movimento já existia. Como a arte postal abrange muitos aspectos e diferentes formas, além de muitas teorias sobre ela, neste breve trabalho discutiremos apenas algumas questões referentes a esta teorização. Para isto, limitaremos o espectro de nossas observações a apenas um tópico: como os editores das publicações coletivas (assemblings) veem estas publicações e as relações de várias ordens que se estabelecem a partir delas.

Segundo Stephen Perkins, o termo "revistas-coletâneas" (assembling magazines) refere-se a um paradigma inovador de publicação que emergiu no começo dos anos 1970, por meio da publicação da revista norte-americana Assembling (1970-1987). Os editores dessa revista teriam começado uma política de inclusão não restritiva de trabalhos em que se convidava o eventual colaborador a enviar mil cópias do que desejasse publicar. A primeira edição teve 42 colaboradores, cujos trabalhos foram reunidos em mil volumes - correspondendo à encadernação de mil exemplares de cada conjunto, composto pela totalidade do material enviado pelos 42 colaboradores. Na avaliação de Perkins:

De maneiras importantes estas revistas invertem o modelo de publicação tradicional: a prerrogativa editorial é abolida, os colaboradores agora se tornam editores em um processo cumulativo que leva ao volume final. De modo mais importante, revistas-coletâneas (assembling magazines) abriram as portas para qualquer um entrar no ônibus da publicação experimental. ${ }^{17}$

De fato, uma das questōes teóricas mais interessantes desse movimento é a representação construída por seus participantes sobre julgamento e seleção, mercado e valor. Vejamos, então, como se constroem os argumentos deles sobre este tema.

16 RAMAN, Ely. Two Views - 26 Years Later: Part 2. In: PERKINS, Stephen, op. cit., p. 20-22.

17 PERKINS, Stephen. Introduction. In: PERKINS, op. cit., 1996, p. 2. 


\section{Seleção e julgamento, mercado e valor, circulação}

O editor de Arte Postale!, Vittore Baroni, declarou em entrevista publicada em 1996:

Em 16 anos, mais de 500 networkers, desde garotos do ensino fundamental até artistas bem respeitados, como Ray Johnson e Ben Vautier, participaram de Arte Postale! No puro espírito da arte postal, nenhuma forma de censura ou seleção sobre as contribuições originais reunidas jamais foi aplicada.

Curiosamente, antes mesmo de fazer a apologia da inclusão absoluta, sem censura, sem edição, Baroni declara que, naquele momento, estava tentando manter a publicação com um peso inferior a 20 gramas ("para economizar nas árvores e no preço do correio") e que preferia focalizar um tema de cada vez:

[...] selecionando as contribuições mais inspiradas e organizando-as de modo a fazer uma afirmação coletiva [collective statement] sobre aquele tópico particular (é claro que todos os que contribuíram, mas não foram reproduzidos no volume ganham uma cópia grátis; incluir sempre tudo seria econômica e tecnicamente impossivel!). ${ }^{18}$

Além do uso do verbo "selecionar", chamo a atenção para o fato de que, se as "contribuições mais inspiradas" foram escolhidas, deduz-se que as "menos inspiradas" (segundo os critérios do editor, é claro) não foram. Baroni também chama a atenção para a ironia de esta publicação sem fins lucrativos estar sendo oferecida por altos preços a colecionadores de arte de vanguarda.

O editor de Assembling (USA), Richard Kostelanetz - que chama esta publicação de "livro", mas aceita também a designação de "magazine",$-{ }^{19}$ mantém o discurso sobre a abertura do processo editorial em que tudo seria aceito, mas declara que os editados da publicação dele eram convidados a enviar uma amostra de seus trabalhos: "Você tinha

18 BARONI, Vittore. Arte Postale!; Editor's Statement. In: PERKINS, Stephen, op. cit., p. 8. Veja-se também o depoimento do editor de YE (Alemanha), Theo Breuer: "Minha edição de YE é naturalmente nāo comercial, alguns portfolios são vendidos a colecionadores para cobrir pelo menos um pequeno percentual dos custos das caixas, selos etc." (BREUER, T. My Mail Art Assembling Magazine. In: PERKINS, op. cit., p. 38.)

19 Cf. HELD JR., John. Assembling Magazines. In: PERKINS, Stephen, op. cit., p. 18: "Assembling começou em 1970. Pedia-se aos colaboradores que submetessem material criativo 'que não seria publicado de outra maneira' (otherwise unpublishable) em unidades de mil cópias preparadas para serem encadernadas alfabeticamente em um livro. O conceito se tornou tão popular que em 1978 Eight Assembling teve de vir à luz em dois volumes." 
de ser convidado. [...] Estou certo de que ninguém foi desconvidado. As pessoas podem ter sido desencorajadas ou encorajadas a desconvidar-se, mas acho que ninguém nunca foi desconvidado".20

O editor de Wall (Bélgica, 1988-1994), Kristof S. Debris, diz que "a questão da qualidade na arte postal" é um velho problema, especialmente em coletâneas (assemblings) que não têm tema, nem prazo de publicação definidos. Embora ele tivesse começado com o objetivo apenas de receber (e publicar) o material, Debris declara: "Mas antes que você perceba a bosta fica pingando de todos os lugares (the crap is pouring from everywhere) e muito rapidamente você compreende o verdadeiro sentido da frase clássica 'qualidade é mais importante do que quantidade"' ${ }_{21}$ Já John Held Jr., ao falar sobre a história das revistas-coletâneas (assembling magazines), ressalta sua feição não comercial:

A arte postal é geralmente um ponto marcado de encontro não comercial para artistas. Como resultado, a ideia de pagar pela inclusão em uma coletânea (assembling) é evitada. O editor assume as responsabilidades da produção e os custos da distribuição em troca da submissão gratuita da obra dos participantes. Isto se torna possível quando um número menor do que o necessário de originais apresentados é incluído. Por exemplo, se 50 participantes enviarem 75 trabalhos, há 25 cópias disponíveis depois dos 50 receberem as cópias deles. ${ }^{22}$

De fato, o editor de Punho23 (Brasil, 1973-), Paulo Bruscky, declara: "Artistas que queiram participar da revista Punho devem enviar 100 cópias de seu trabalho". ${ }^{24}$ No caso de Tabu, seu editor, Joaquim Branco, esclarece que este era um pequeno jornal/revista editado pelo grupo Totem, de Cataguases, impresso em offset doméstica $($ multilicht $)$, com periodicidade, tiragem e número de páginas variáveis, que

\footnotetext{
20 PERKINS, Stephen. Assembling; an Interview with R. Kostelanetz. In: PERKINS, Stephen, op. cit., p. 13.

21 Wall; Editor s Statement. In: PERKINS, op. cit., p. 36-37, p. 36. Cf. na mesma página: "Como você controla a qualidade de uma coletânea (assembling) ou de qualquer outro projeto artístico? É claro que é preciso mais do que a soma total da qualidade das obras singulares. Já vi magazines com conteúdo medíocre, enquanto, em outras vezes, o trabalho do editor ficou aquém da qualidade do conteúdo."

22 HELD JR., John. Assembling Magazines. In: PERKINS, Stephen, op. cit., p. 18.

23 Cf. BRUSCKY, Paulo. Editorial Statement. In: PERKINS, Stephen, op. cit., p. 32:"A revista Punho é idealizada por escritores e artistas de Pernambuco. Foi primeiramente escrita e desenhada em papéis para stencil a álcool em mesas de bar no Recife." A capa do catálogo desta exposição norte-americana reproduz exatamente a capa do número 5 de Punho (1996).

24 Idem, ibidem.
}

156 - JOBIM, José Luís, A arte postal/ arte-correo/ mail art como sistema 
começou a circular em novembro de 1976 e encerrou as atividades em abril de 1980 , completando 11 números:

[...] no Tabu só aceitávamos trabalhos vanguardistas ou que tivessem alguma proposta nesse sentido. O Tabu era financiado pela atividade teatral e musical do grupo, e quando não havia dinheiro, pelos próprios participantes em quantias módicas, já que se tratava de publicação impressa em Cataguases, em um sistema rudimentar. ${ }^{25}$

Indagado sobre a lógica predominante no Tabu - se a de receber todo o material já com o número de cópias correspondente à tiragem, ou só uma cópia e o editor fazer todas as reproduções -, Joaquim Branco respondeu: "Regularmente, como editores, fazíamos as reproduções na publicação, mas algumas vezes recebíamos textos avulsos, já com todas as cópias. Nesse último caso, apenas encartávamos o material recebido". ${ }^{26}$

Examinando o depoimento dos editores das revistas-coletâneas, percebe-se que não é uma prática geral entre eles assumirem totalmente os custos de produção e distribuição. A editora de Estudio (USA, 1988-1990), Sheila Holtz, por exemplo, declara que "cada participante pagava \$1,00" ${ }^{27}$ Theo Breuer, editor de YE (Alemanha, 1993 -), afirma que "alguns portfólios são vendidos a colecionadores para cobrir pelo menos um pequeno percentual dos custos das caixas, selos etc." ${ }^{28}$ No fim das contas, parece, isto sim, que em geral a questão de cobrir os custos estava longe de ser colocada em termos do equacionamento da atividade para, pelo menos, não gerar prejuízo, como indica o depoimento de Patricia Collins, editora de It's in the box (Grã-Bretanha, 1995): "Eu não pensava sobre o lado das vendas, publicidade, distribuição até que tivesse terminado e ainda não compreendi isto direito.".

Talvez possamos dizer que se trata de um tipo de publicação que não tem os custos de publicações "de massa", nem visa a um público amplo, geral e irrestrito; por isso, as várias formas de custeio parcial ou total de empreendimentos desse tipo (pagamento de custos pelos colaboradores [desde o custo da reprodução das cópias do material enviado para ser encadernado, até despesas de correio, selos etc.], patrocínios etc.) estão

25 RIBEIRO Filho, Joaquim Branco. Sobre Tabu. Arquivo eletrônico enviado em 07 maio 2007.

26 Idem, ibidem. Resposta a questionário em arquivo eletrônico. Enviada em 12 maio 2007.

27 HOLTZ, Sheila. Estudio; Editor's Statement. In: PERKINS, op. cit., p.22.

28 BREUER, Theo. My Mail Assembling Magazine: YE! In: PERKINS, op. cit., p. 38.

29 COLLINS, Patricia. It's in the Box; Artist's Statement. In: PERKINS, op. cit., p. 45. 
acopladas ao circuito restrito em que circulam os produtos artísticos, circuito este integrado antes de mais nada pelos próprios colaboradores que recebem a publicação com sua obra encadernada na forma de revista-coletânea. Esta ênfase nos componentes do circuito em que circulavam os assemblings - composto, como vimos, predominantemente pelos próprios artistas colaboradores - explica depoimentos como o de Charles Stanley, editor de Yurt Yet (USA, 1979): "Ao publicar, eu travei relações com muitos outros artistas, e muitas outras publicações, e neste sentido, ao publicar tantos outros mais, tive um senso de fortalecer as comunidades artísticas e sociais em que estava envolvido" ${ }^{30}$

No caso de Tabu, segundo seu editor, os colaboradores recebiam às vezes mais de um exemplar (para redistribuição), e o restante seguia para outros poetas mais ligados ao movimento (do Brasil e do exterior), para críticos e professores da área interessados (também do Brasil e do exterior), guardando-se alguns para o arquivo pessoal do próprio Joaquim Branco. ${ }^{31}$

Ely Raman, coeditor de 8 X1o PORTFOLIO (USA, 1970-1972), diz que, na época, "estava muito envolvido com a ideia de projetos de distribuição alternativa - assim como com a ideia de usar materiais e técnicas não tradicionais para fazer arte." ${ }^{32} \mathrm{E}$ responde à pergunta sobre por que teria parado de editar aquela publicação, alegando razões econômicas, entre outras: "Acho que começou a virar um emprego e eu já tinha um. A despesa de produzi-la (trabalho+\$) me deu uma boa desculpa para sair" ${ }^{33}$ A editora de Mail Order Art (USA, 1972), Patricia Tavenner, diz: "Então, agora qualquer mulher artista postal pode enviar 75 páginas, \$ 5 para encadernação e correio" ${ }^{34}$

30 STANLEY, Charles. YURT YET; Editor s Statement. In: PERKINS, op. cit., p. 42.

31 RIBEIRO FILHO, Joaquim Branco. Resposta a questionário em arquivo eletrônico. Enviada em 12/05/2007. Veja-se também a resposta à minha pergunta: "JL: - Tabu tinha e pedia colaboraçōes estrangeiras? Em caso positivo, por favor, enumere os colaboradores.

Joaquim Branco: - Com a corrente criada pela intensa atividade de intercâmbio - eu chegava a receber cerca de dez cartas por dia -, não era necessário pedir colaboração. Tudo era espontâneo e natural. Os colaboradores brasileiros mais atuantes eram: Paulo Bruscky, Hugo Pontes, Moacy Cirne, Álvaro e Neide de Sá, Wlademir Dias Pino, Dailor Varela, Márcio Almeida, Domingos Diniz, Ricardo Alfaya, Adrino Aragão. Entre os estrangeiros: Dámaso Ogaz, Ednodio Quintero (Venezuela), Clemente Padin (Uruguai), Edgard-Antonio Vigo (Argentina), Guillermo Deisler (Chile), Cavellini (Itália), Teresinka Pereira, Stefan Baciu (EUA), César Toro Montalvo (Peru), Julien Blaine (França), César Espinosa (México), Virgitio A. C. Matos, Melo e Castro, Ana Hatherly, Seth Wade (Canadá), Roberto Mathieu e German Suescun (Colômbia), Timm Ulrichs, Klaos Staeck, Robert e Ruth Rehfeldt (Alemanha)."

32 RAMAN, Ely. Two Views - 26 Years Later: Part 2. In: PERKINS, Stephen, op. cit., p. 21.

33 Idem, ibidem. Raman termina dizendo que não conseguiu ser contemplado com o pedido de patrocínio de $\$ 2.800,00$ e que, talvez, se tivesse pedido "\$18.000,00 (1978 dollars)" poderia ter obtido...

34 TAVENNER, Patricia. Mail Order Art; Editor s Statement. In: PERKINS, Stephen, op. cit., p. 48.

158 - JOBIM, José Luís. A arte postal/ arte-correo/ mail art como sistema 
Já os editores de Leopold Bloom (Hungria, 1995-), Peter Abajkovics, Károly Bonyhadi, Laszlo e Akos Szekely, fazem a apologia do próprio circuito restrito:

Os primeiros quatro números de Leopold Bloom foram publicados com tiragem de 75 exemplares. Isto pode parecer um circuito um pouco fechado, mas isto nos permitiu publicar exemplares originais, assinados. Somente autores e patrocinadores [...] podem obter um exemplar. Nosso periódico é também um experimento para investigar se há ainda trocas reais vigentes entre artistas e pensadores como honorário intelectual e relação. ${ }^{35}$

É interessante notar nesta citação o valor atribuído aos exemplares exatamente por serem poucos e possuírem assinatura; ao mesmo tempo, temos uma reprodução seriada, mas como a série é limitada e restrita a um público seleto, valoriza-se mais. Esta valorização da assinatura autoral remete a certa concepção de arte, ao mesmo tempo relacionada a aspectos derivados da visão romântica do autor como gênio cuja produção deveria ser valorizada, por expressar este ego original e único - e à consolidação progressiva da legislação sobre direitos autorais, que cada vez mais referia a propriedade da "mercadoria" artística a seu autor.

A menção explícita aos "patrocinadores" remete ao equacionamento econômico desta produção, e não constitui novidade, pois vimos o editor de YE afirmar que alguns portfólios eram vendidos a colecionadores, e o editor de Arte Postale! dizer que esta publicação sem fins lucrativos era oferecida por altos preços a colecionadores de arte de vanguarda.

Contudo, é importante assinalar que este equacionamento econômico e este destaque à individualidade autoral apresentam-se em contradição com a definição de arte-correo dada pelo COLECTIVO-3, no catálogo da exposição realizada no Colóquio Sobre Arte Correo Colectivo, entre 17 e 27 de maio de 1983, na Universidad Autonoma Metropolitana - Xochimilco:

Trata-se de um processo de produção e circulação do trabalho artístico que demanda o diálogo e a participação do interlocutor, à margem dos cânones da "obra única, irrepetível e genial", e de todas suas vertentes de mercantilismo, galerias e jurados, "marchands" e outros. ${ }^{36}$

35 ABAJKOVICS, Peter; BONYHADI, Károly; SZEKELY, Laszlo \& Akos. Editor s Statement. In: PERKINS, Stephen, op cit., p. 25.

36 POEMA colectivo. Revolución. Xochimilco (México): Universidad Autonoma Metropolitana - Xochimilco, 1983, p. 1. Catálogo.

Teresa revista de Literatura Brasileira [10|11]; Sāo Paulo, p. 142-161, 2010. - 159 
Esta representação da produção artística como "marginal" também tem, é claro, raízes antigas na história da literatura, e podemos encontrar muitos exemplos dela desde o romantismo. Nos dias de hoje, mesmo artistas que vivem no chamado "primeiro mundo" argumentam que há um sentimento de isolamento do artista, que não se adapta ao molde de competição - responsável pela transformação do mercado de arte em um negócio de muitos milhões de dólares - e permanece sem reconhecimento da mídia e do público (público este que necessitaria da mídia para tomar conhecimento da arte e do artista). ${ }^{37}$

Acrescente-se que esta "distância da mídia" pode ser transformada também em argumento a favor da qualidade do produto que não consegue veiculação pelos meios de massa: se é para "todos", então não pode ser bom, deve ser repetitivo, trivial, vulgar ou qualquer outro adjetivo análogo. Philadelpho Menezes, por exemplo, tratando da poesia experimental no Brasil, em entrevista concedida à revista Fiction International, também transforma a distância da mídia em aspecto positivo:

Rememorando os anos 70, é fácil mostrar que os poetas mais interessantes [...] são os menos ativos. Isto é devido ao fato de que, em virtude da busca de novas soluções para as questões da poesia experimental e de modo a evitar repetição, os poetas mais inventivos acabaram diminuindo seu ritmo de publicaçāo. Alguns dos mais típicos representantes desta linhagem, como o poeta paulista Villari Herrmann, não publicaram mais de dez poemas nas últimas três décadas de produção.

Levando em conta estas observações, podemos identificar - além de Herrmann alguns outros, como Hugo Mund Jr., Márcio Almeida, Sebastião Nunes, Joaquim Branco, Hugo Pontes e um sobrevivente do grupo Noigandres, Ronaldo Azeredo. Todos estes poetas tiveram muito pouca cobertura na imprensa. Seu reconhecimento ficou muito restrito ao círculo dos próprios poetas experimentais..$^{38}$

\section{O circuito e a subjetividade dos artistas}

O que significaria um circuito de produção cultural transnacional fortemente assentado em produtores culturais? Para alguns, como Pascal Lenoir, editor de Mani

37 JACOB, John. Mailart: in theory. In: Mail art about mail art. Dallas: Richland College, 1984, p. 12. Catálogo.

38 POLKINHORN, Harry. Interview with Philadelpho Menezes. Rev. Ficction International, San Diego: State University Press, n. 28, p. 133, 1995.

160. JOBIM, José Luis. A arte postal/ arte-correo/ mail art como sistema 
Art (França, 1995), é a própria inserção neste circuito específico que justifica a sua atuação nele: "Minha experiência? Uma longa e intensa comunicação com centenas de artistas do mundo inteiro. Muito tempo se passou e pouco dinheiro foi dispendido... Em troca, uma formidável impressão de criação e prazer". ${ }^{39}$ Laura Poll, editora de Malcontent (USA, 1994-), resume o argumento padrão de muitos editores de revistas-coletâneas: "Tudo que eu posso dizer é que publicações coletâneas (assembled issues) são fáceis (eu não tenho de escolher conteúdo e diagramá-lo), baratas (sem custos de impressão) e Divertidas! Adoro participar delas também".40

Outros, como Bill Gaglione, editor de Stampzine (USA, 1995), chamam a atenção para o aspecto físico da editoração, que frequentemente envolvia reuniões de amigos/artistas para preparar todos os exemplares, com o material enviado pelos colaboradores:

Outro aspecto das coletâneas (assemblings) era que eu gostava da preparação, porque costumava chamar todos os meus amigos e é um modo social bom de ficar juntos, em vez de só ficar sentados lá bebendo ou ficando chapados - o que fizemos, mas trabalhamos e foi divertido. ${ }^{42}$

O editor de LlRrR (Itália, 1985-1995), Roberto Zito, declara que o que o motivou inicialmente foi o desejo de estar no movimento postal, por acreditar nele, mas acha que a proposta de fomentar o contato e a troca entre artistas foi um objetivo raramente alcançado. ${ }^{42}$ Zito também coloca a questão de como ele se vê a si mesmo e deseja ser visto por outros:

39 LENOIR, Pascal. The Secret Life of Pascal Lenoir. In: PERKINS, Stephen, op. cit., p. 28.

40 POLL, Laura. Maicontent; Editor's Statement. In: PERKINS, Stephen, op. cit., p. 27-28.

41 PERKINS, Stephen. Interview with Bill Gaglione, op. cit., p. 34.

42 Cf. a entrevista com Zito, in PERKINS, op. cit, p. 25-27, p. 26. "Luca Miti: "Por que você fundou a LLRRR?"

Roberto Zito: Porque há dez anos atrás eu pensava que o fluxo do correio era o argumento central de um movimento cultural sério e assim eu queria estar nele, então havia muitas revistas coletâneas (assembling magazines) na rede de trabalho - eu queria a minha - para distribuir melhor a arte postal e me envolver no movimento e porque, então, eu acreditava, como acredito hoje.

LM: O que você sente que [a arte postal] ofereceu à comunidade de artistas que estava envolvida com ela? RZ: A chance de estar envolvida com o movimento postal e a chance concreta de ter contato comigo, esta aconteceu com duas ou três pessoas, os outros participaram, receberam seu exemplar e acabou. Este é um aspecto realmente negativo. Muitas pessoas se inseriram nesta rede de trabalho, como em muitas outras situaçōes de grupo, e permaneceram insatisfeitas porque estavam esperando por não sei o quê e desapareceram. Devo dizer que durante os dez anos em que trabalhei com grande sofrimento a maior parte dos participantes fez isto e desapareceu. 
Não sou apenas um performático e pintor - todos estes são rótulos -, mas um operador visual, eu tento me expressar, falar com outros, se os outros estão me escutando, através de imagens. A imagem pode ser ações, e naquelas ocasiões sou um performático, algumas vezes pode ser imagens pintadas, e naquela ocasião sou um pintor; quando sou um artista postal, contribuo para o movimento postal com envelopes, selos de borracha, pacotes entregues em mãos e nisto há também um magazine de arte postal. ${ }^{43}$

Interessante notar esta mobilidade autoclassificatória, até porque no site ${ }^{44}$ ele aparece classificado como "poeta e escritor". Aliás, se há artistas neste movimento que se autoclassificam exclusivamente como poetas - este é o caso de Joaquim Branco, por exemplo -, outros há que se classificam como artistas plásticos; como já dissemos, a própria natureza do movimento, que permite a combinação do verbal com o visual, pode explicar essa possibilidade de diferença na autorrepresentação dos participantes.

\section{A arte postal, as transferências e as trocas culturais}

Joaquim Branco diz que, com seu desenvolvimento mundial, a arte postal desponta em todos os lugares ao mesmo tempo e sem chefias ou nacionalidade de comando, permitindo o acesso de todos os poetas e sendo também o elo que os une pelo correio e mais recentemente também pela internet. ${ }^{45}$ Vê-se, assim, que a imagem construída para este movimento não é a tradicional em que um centro origina uma arte que é imitada pela periferia. Como não há a representação do antes, precursor, original, gerado no centro, também não há a do depois, posterior, imitador, surgido na periferia. Cria-se, isto sim, um sentido de sincronicidade - trata-se de uma arte vista como contemporânea e produzida ao mesmo tempo em vários países diferentes - e de ausência de hierarquias rígidas, em que não se trabalha com a noção de que na "periferia" se imita o "centro", mas com a ideia de que se pode estabelecer um circuito em que todos os artistas envolvidos sejam protagonistas ao mesmo tempo.

Assim, o conjunto de práticas artísticas que resultou nas revistas-coletâneas não tinha por trás de si uma gama de instituições (editoras, universidades, galerias, museus etc.) que poderiam assegurar a sua reprodução, a conexão entre elas e uma

\footnotetext{
43 Idem, ibidem.

44 <http://www.basilicata.cc/artistilucani/zito/index.htm>. Acesso em: 24 maio 2007.

45 RIBEIRO FILHO, Joaquim Branco, op. cit., p. 114.
}

162 - JOBIM, José Luís. A arte postal/ arte-correo/ mail art como sistema 
estabilidade maior do sistema em que se inseriam. No entanto, os artistas transformaram esta falta de apoio institucional em mérito, ao criarem argumentos para desvalorizar as formas de poder vigentes nos circuitos mais tradicionais, começando pelo princípio da seletividade que aquelas instituições implicam. Porque este princípio de seletividade, estabilizado em um conjunto de instituições, fornece a matriz das classificações e legitima as desigualdades e as hierarquias na publicação, sua suposta ausência produz um efeito de sentido de igualdade entre todos os participantes destas publicações - ainda que, de fato, conforme comprovamos, continuem ocorrendo julgamento e seleção no próprio processo de publicação destas revistas. De todo modo, é relevante assinalar que este circuito das revistas-coletâneas, independente do convencional, coloca novas questões para discussão. Se ele é muitas vezes restrito aos próprios artistas participantes, isto não lhe tira o caráter de extrema agilidade de circulação dos produtos para seu público-alvo, nem a transnacionalidade do sistema de trocas e transferências artísticas que implementou.

Além da agenda transnacional do movimento, e da defesa de uma posição predominantemente inclusiva para todos os possiveis participantes, é interessante relembrar as palavras de Géza Perneczky, ${ }^{46}$ que chama a atenção para o fato de esta rede de artistas ter-se originado primariamente nas províncias, onde as longas distâncias, a falta de contatos sociais e a opressão política (na Europa do Leste e em alguns países da América Latina) forçaram "os artistas a contornarem os canais oficiais da vida pública e a estabelecerem contatos alternativos". Tudo isto indica, pelo menos, que há muitas questões relevantes a serem discutidas sobre este movimento, e ainda muito a fazer sobre ele, em pesquisas futuras.

José Luís Jobim é professor da Universidade do Estado do Rio de Janeiro e da Universidade Federal Fluminense. 